\title{
Desenvolvimento do sistema financeiro e pobreza no Brasil: uma análise multivariada *
}

\author{
Tânia M. M. Fialho ** \\ Frederico G. Jayme Jr. ${ }^{* * *}$ \\ Ana Maria Hermeto ${ }^{* * * *}$
}

\begin{abstract}
Resumo
Nas últimas décadas, diversos estudos têm enfatizado as inter-relações entre o desenvolvimento do sistema financeiro e o crescimento econômico. Análises teóricas e empíricas sugerem que o desenvolvimento do sistema financeiro exerce um efeito positivo sobre a taxa de crescimento econômico, gerando impactos no crescimento da renda e na redução das taxas de pobreza. Este estudo procurou investigar a efetividade do desenvolvimento do sistema financeiro como um instrumento de promoção do crescimento econômico, da ampliação da renda e da redução da pobreza, utilizando dados das unidades federativas brasileiras, no período 1995-2008 e empregando a técnica econométrica de análise da correlação canônica, visando confrontar as predições teóricas com o comportamento empírico das variáveis de interesse ao longo do tempo. Os resultados obtidos denotaram que o desenvolvimento do sistema financeiro demonstrou ter um bom poder preditivo da variância dos compostos de variáveis correlatos à renda e a pobreza.
\end{abstract}

Palavras-chave: Desenvolvimento financeiro; Pobreza; Renda; Crescimento econômico; Correlação canônica.

\begin{abstract}
Financial development and poverty in Brazil: a multivariate analysis

In recent decades, several studies have highlighted the relationship between the development of the financial system and economic growth. Theoretical and empirical analyses suggest that financial system spurs economic growth, generating impacts on income growth and reducing poverty rates. This study investigated the effectiveness of the development of the financial system as a tool to promote economic growth, increase income and reduce poverty, using data on the Brazilian states from 1995 to 2008. We employ canonical correlation in order to compare the theoretical predictions with the empirical behavior of the variables of interest over time. The results show that the development of the financial system has demonstrated a sound predictive power of the variance of the compounds of the variables related to income and poverty.
\end{abstract}

Keywords: Financial development; Poverty; Income; Economic growth; Canonical correlation.

JEL E00, E20, E44.

\footnotetext{
${ }^{*}$ Artigo recebido em 8 de maio de 2014 e aprovado em 8 de janeiro de 2016.

** Professora da Universidade Estadual de Montes Claros (Unimontes) / Programa de Pós-Graduação em Desenvolvimento Econômico e Estratégia Empresarial (PPGDEE), Montes Claros, MG, Brasil. E-mail: tania.unimontes@gmail.com.

**** Professora da Faculdade de Ciências Econômicas da Universidade Federal de Minas Gerais (Face/Cedeplar/UFMG), Belo Horizonte, MG, Brasil. E-mail: gonzaga@ cedeplar.ufmg.br.

${ }^{* * * *}$ Professora da Faculdade de Ciências Econômicas da Universidade Federal de Minas Gerais, Belo Horizonte, MG, Brasil. E-mail: ahermeto@ cedeplar.ufmg.br.
} 


\section{Introdução}

A relação entre desenvolvimento do sistema financeiro e crescimento econômico está longe de ser consensual na literatura econômica. Avaliações empíricas diversas indicam que o desenvolvimento do sistema financeiro exerce um efeito positivo sobre a trajetória das taxas de crescimento econômico, especialmente pela capacidade de estimular os níveis de produto e emprego dos diversos países. Ademais, crescente ênfase tem sido depositada no acesso aos serviços financeiros, como elemento essencial à promoção do desenvolvimento, especialmente por sua capacidade de afetar o comportamento da economia, da pobreza e da equalização da renda.

Fields (2001) argumenta que um sistema financeiro pouco desenvolvido concorre para a persistência da pobreza, maior desigualdade de renda e para um crescimento econômico mais lento, na medida em que restringe o acesso da população pobre ao crédito e a outros produtos e serviços financeiros, passíveis de garantir sua participação efetiva na atividade econômica, quer seja para iniciar um ciclo de produção, geralmente em pequenos empreendimentos, ou para o consumo de bens e serviços, tais como educação, saúde e lazer, essenciais à ampliação da renda e da qualidade de vida.

A despeito da existência de análises sistemáticas e recorrentes correlacionando o desenvolvimento do sistema financeiro com o crescimento econômico no Brasil, são raras e ainda preliminares as incursões nos efeitos que isto pode gerar nos indicadores de pobreza e renda do país. Sem desconsiderar a relevância desses estudos para a compreensão do processo de desenvolvimento brasileiro, importa, todavia, ressaltar que, especialmente em economias caracterizadas pela alta concentração de renda, os benefícios decorrentes do crescimento econômico podem ser desigualmente distribuídos, prejudicando as camadas mais pobres da população, aprofundando as disparidades regionais e prejudicando, ou até mesmo anulando, os efeitos benéficos sobre a pobreza. Ademais, segundo Kumar (2004), os próprios diferenciais na renda e na densidade populacional, bem como os elementos inerentes à lógica da dinâmica do sistema financeiro, podem determinar a concentração da oferta dos serviços financeiros em áreas com níveis de rendimentos mais elevados. Dessa forma, especialmente para países como o Brasil, caracterizado por uma ampla dimensão territorial e por níveis elevados de desigualdade e de concentração da renda, considerar apenas o impacto indireto - via crescimento econômico - que o desenvolvimento do sistema financeiro deve exercer sobre a pobreza, pode significar restringir a análise de uma questão que é muito mais ampla.

A partir desta perspectiva, este trabalho objetiva ampliar a compreensão das possíveis interações entre o sistema financeiro, a taxa de pobreza e a renda domiciliar 
per capita no Brasil. Sua relevância encontra-se no fato de que pode vir a se constituir em uma contribuição complementar à literatura pertinente ao tema, sobretudo por enfatizar os efeitos que o desenvolvimento do setor financeiro exerceu sobre as trajetórias da pobreza e da renda no Brasil no período compreendido entre 1995 e 2008. O trabalho utiliza a correlação canônica para preencher uma lacuna existente na literatura empírica, até então sob o domínio de métodos baseados em análises cross-country ou, em alguns casos, da utilização dados em painel. Os resultados obtidos denotaram que o desenvolvimento do sistema financeiro gerou efeitos positivos no crescimento da renda e na redução das taxas de pobreza das unidades federativas brasileiras, no período 1995-2008, o que demonstra um bom poder preditivo da variância dos compostos de variáveis correlatos à renda e a pobreza.

Além dessa introdução, a seção 1 apresenta uma breve revisão da literatura pertinente ao tema analisado; a seção 2 apresenta o método, a base e fonte de dados, a seção 3 apresenta os principais resultados e, na última seção, são delineadas algumas conclusões.

\section{Desenvolvimento do sistema financeiro, pobreza e renda}

A concepção de que o desenvolvimento do sistema financeiro favorece a população mais pobre, tanto de forma indireta, via crescimento econômico, quanto de forma direta, por estimular o empreendimento de iniciativas econômicas autofinanciadas deve, em grande medida, ser creditada a McKinnon (1973). O autor argumenta que, em economias com sistemas financeiros pouco desenvolvidos, a acumulação de poupança prévia é complemento essencial aos bens de capital para garantir a realização do investimento. Assim, a pobreza e a incapacidade de obter empréstimos pode se constituir em uma significativa barreira à adoção de tecnologias simples e produtivas. $\mathrm{O}$ autor enfatiza, ainda, que mesmo com o acesso restrito da população pobre ao crédito, forçando, na maioria das vezes, uma situação de autofinanciamento, o sistema financeiro pode possibilitar oportunidades lucrativas para a poupança. Dessa forma, a intermediação financeira afeta a pobreza, tanto por meio das operações de crédito, quanto via remuneração dos saldos monetários que, em última instância, configuram a poupança prévia necessária ao investimento, o que, em essência, constitui o "conduit effect" de McKinnon", sobre o qual repousa a principal justificativa para a defesa da liberalização do sistema financeiro.

Ao afetar a trajetória das taxas médias de crescimento da economia, é de se esperar que o sistema financeiro exerça, também, impactos positivos sobre a pobreza

(1) De acordo com McKinnon (1973) e Shaw (1973), a liberalização financeira favorece a poupança, o investimento e o crescimento econômico. Em contraposição ao enfoque tradicional sobre fundos emprestáveis, os autores ponderam que o investimento é positivamente relacionado com a taxa de juros real. Subjacente a tal argumento repousa a ideia de que o aumento na taxa de juros aumenta o volume da poupança e, portanto, dos fundos para investimentos, o que foi denominado de "conduit effect". 
e a distribuição de renda, dado o efeito do crescimento econômico na criação e/ou ampliação de oportunidades de trabalho. Mesmo sendo condição necessária, o crescimento econômico per si, pode não ser suficiente para reduzir os indicadores de pobreza. É fato que a teoria do trickle down ${ }^{2}$ defende que o crescimento econômico exerce um efeito favorável sobre a renda como um todo. Contudo, deve-se levar em conta que a concentração da riqueza nas camadas da população com níveis de rendimentos mais elevados, ao contrário de beneficiar os pobres, pode ampliar e aprofundar as desigualdades, prejudicando e mesmo anulando os efeitos positivos do crescimento. Ao desenvolverem um modelo em que analisam a interação entre crescimento e distribuição de renda, Aghion e Bolton (1997, p. 152) demonstram que o efeito tricle down sobre a pobreza é afetado pelas imperfeições do mercado financeiro, asseverando que "the trickle down mechanism is not sufficient to eventually reach an efficient distribution of resources, even in the best possible scenario"3. Contudo, evidências apresentadas por Dollar e Kraay (2002) não denotam a existência do mecanismo trickle-down quando examinam a relação entre o crescimento da renda média do pobre e o crescimento da renda média em uma amostra de 92 países quer sejam desenvolvidos ou em desenvolvimento. Demonstram que a renda média do quinto mais pobre varia à mesma taxa da variação da renda média dos diversos países. Demonstram também que políticas macroeconômicas de promoção do crescimento relacionadas à redução da inflação, adequado tamanho do setor público, solidez do sistema financeiro, respeito à legislação e abertura ao comércio internacional elevam a renda média, mas com pouco efeito sobre a distribuição de renda (Dollar; Kraay, 2002, p. 218). Na perspectiva dos autores isso suporta a ideia de que a adoção de políticas macroeconômicas centradas na disciplina fiscal, estabilidade econômica e abertura comercial, na média, aumenta a renda do pobre na mesma proporção do aumento de renda de outras famílias. Os resultados, portanto, demonstram que políticas de austeridade, sem combinações com políticas distributivas, não produzem efeito sobre a distribuição da renda e, por conseguinte, sobre a pobreza relativa.

Falhas e imperfeições do mercado financeiro, especialmente aquelas relacionadas às assimetrias de informações, implicam em restrições ao crédito que atingem diretamente a população mais pobre. Em geral, a alocação do crédito pelo sistema financeiro é feita fundamentada em garantias que os beneficiários podem

(2) Para a denominada teoria trickle-down, quando a economia cresce, parte da riqueza acumulada nas camadas de renda mais elevadas é transferida aos pobres, por meio dos efeitos dinâmicos produzidos na geração de emprego e renda. Assim, nessa perspectiva, o crescimento econômico beneficia indistintamente toda a população.

(3) Aghion e Bolton (1997) mostram que a acumulação de capital, decorrente do crescimento econômico, amplia inicialmente a desigualdade de renda, dado o alto custo de remuneração do capital que implica em uma maior concentração da riqueza. Posteriormente, a maior acumulação de capital acirra a concorrência, reduzindo a taxa de juros, o que permite maiores ganhos aos tomadores de empréstimos, em geral a classe média e pobre, reduzindo, portanto a desigualdade. Nesse sentido, os autores argumentam que essa dinâmica pode gerar uma curva em "U" invertido, conforme preconizado por Kuznets. 
propiciar e nas relações que estes já têm estabelecidas com as instituições financeiras, o que, quase sempre, exclui a parcela da população pobre ou com renda insuficiente para atender às exigências impostas pelo setor. Essa situação torna-se mais grave em países com baixa intensidade de desenvolvimento do sistema financeiro caracterizados, dentre outros aspectos, por uma reduzida cobertura espacial dos serviços financeiros, pelo excesso de exigências para inserção no sistema e pela falta de regulação e de políticas específicas que beneficiem os pobres. Isto resulta em restrições à capacidade dessa parcela da população de participar de forma plena da atividade econômica, limitando suas possibilidades de sair da condição de pobreza e galgar melhores posições na escala de distribuição de renda, conforme destaca Zhuang et al. (2009, p. 12).

Banerjee e Newman (1993) avaliam como a interação entre as decisões de trabalho dos indivíduos e a distribuição de riqueza afeta o desenvolvimento econômico. Ressaltam que a existência de contratos de trabalho só ocorre em uma situação de desigualdade, uma vez que, ante as imperfeições do mercado de capitais, o trabalhador pobre escolhe trabalhar por uma remuneração superior àquela que receberia caso atuasse por conta própria. Do mesmo modo, os ricos tornam-se empresários, levando o desenvolvimento a depender da distribuição inicial da riqueza. Galor e Zeira (1993), por seu turno, levam em conta imperfeições do mercado de crédito e as indivisibilidades do investimento em capital humano para analisar o papel da distribuição inicial da riqueza na macroeconomia, como uma explicação adicional da persistência das diferenças no produto per capita de diversos países. Piketty (1997), utilizando o modelo de Solow, demonstra a existência, no longo prazo, de múltiplos estados estacionários em um cenário de políticas de crédito restritivas e elevadas taxas de juros. Argumenta que para cada taxa de juros de equilíbrio existe uma distribuição de riqueza única e estacionária, que depende das condições históricas. Nesse contexto, é possível que uma sociedade marcada pela pobreza pode, no longo prazo, melhorar suas condições de distribuição de riqueza em um horizonte temporal finito. Da mesma forma, o inverso também é verdadeiro e inexiste, portanto, armadilha de pobreza inescapável, ainda que o nível de riqueza e de mobilidade de renda possa variar entre os múltiplos estados estacionários.

Outra vertente teórica, inspirada nos princípios desenvolvidos por Kuznets $(1955)^{4}$, sustenta a existência de uma relação não linear entre o sistema financeiro, o desenvolvimento econômico e a distribuição de renda. Greenwood e Jovanovic (1990) advogam que nos estágios iniciais do processo de desenvolvimento econômico, o caráter restrito do sistema financeiro limita o acesso a estes serviços a

(4) Utilizando dados em séries temporais para diversos países, Kuznets demonstra existir uma relação entre o padrão de desigualdade e o crescimento econômico que, em síntese, toma a forma de um "U" invertido - o que passou a ser conhecido na literatura como Curva de Kuznets - indicando que a desigualdade aumenta no curto prazo com o crescimento econômico, passando, no longo prazo, a decrescer, à partir de um determinado ponto.

Economia e Sociedade, Campinas, v. 25, n. 1 (56), p. 247-278, abr. 2016. 
uma pequena parcela da população - em geral, aquela de maiores níveis de renda o que promove a concentração da renda, ampliando a desigualdade. Na fase intermediária do desenvolvimento econômico, elevam-se as taxas de crescimento da economia e da poupança, ao mesmo tempo em que se configura uma estrutura financeira mais intensa, com a ampliação do acesso aos serviços financeiros, o que afeta positivamente a distribuição de renda, reduzindo a desigualdade. A fase final é marcada pela existência de um sistema financeiro já bem estruturado, por taxas de poupança declinantes e por uma distribuição de renda relativamente estável, com uma tendência de aumento da desigualdade. Essa dinâmica, em síntese, reflete uma curva em "U" invertido entre o desenvolvimento do sistema financeiro e o comportamento da distribuição de renda, seguindo os pressupostos teóricos estabelecidos por Kuznets (1955).

Igualmente importante para entendimento da relação entre desenvolvimento financeiro, pobreza e desigualdade de renda, são os estudos fundamentados no princípio de causação circular cumulativa de Myrdal (1957). Nessa perspectiva, um sistema financeiro espacialmente concentrado e pouco desenvolvido pode se constituir em um fator relevante a obstaculizar o crescimento econômico, ampliando a pobreza e a desigualdade de renda. Em um sistema financeiro pouco desenvolvido, as restrições ao crédito, decorrentes das baixas taxas de poupança e depósitos, prejudicam os fluxos de capital para investimentos produtivos, reduzindo a eficiência na alocação dos recursos, o que afeta negativamente o crescimento econômico e a renda, mantendo ou, em situações mais adversas, intensificando a pobreza e a desigualdade. Na sequência, as reduções das taxas de crescimento econômico e da renda deprimem os níveis de poupança, o que pode implicar na contração do sistema financeiro, levando a economia a uma armadilha da pobreza, conforme sugerem Berthelemy e Varoudakis (1996).

Dow (1982 e 1987), ao estabelecer o diálogo entre a teoria keynesiana e a teoria da causação circular cumulativa de Gunnar Myrdal (1957), utilizando elementos da teoria do desenvolvimento dependente (centro-periferia), contribui para o entendimento dos impactos espaciais do sistema financeiro. Nessa concepção, regiões com um sistema financeiro pouco desenvolvido apresentam taxas de depósitos e de poupança baixas, o que limita as operações de crédito e leva a uma baixa competitividade do setor. Por outro lado, a instabilidade e taxas de crescimento deprimidas que geralmente caracterizam estas regiões, geram expectativas que determinam uma alta preferência pela liquidez. Assim, a livre mobilidade de capitais favorece a concentração espacial do sistema financeiro, posto que as forças do mercado tendem a promover a saída de capitais das regiões menos desenvolvidas (periferia) para as regiões mais desenvolvidas (centro), o que irá fomentar círculos viciosos e resultar em um processo de desenvolvimento regional desigual. Em síntese, Myrdal (1957, p. 41) observa que "estudos em muitos países revelam como o sistema bancário, quando não controlado para operar de maneira diferente, tende a 
transformar-se em instrumento que drena as poupanças das regiões mais pobres para as mais ricas e mais progressistas, onde a remuneração do capital é alta e segura".

Segundo Dow (1982), as condições econômicas prevalecentes nas regiões periféricas - caracterizadas por estruturas produtivas limitadas, grande dependência em relação às regiões centrais, maior suscetibilidade à volatilidade econômica, níveis de renda deprimidos, arranjos institucionais frágeis e oportunidades de investimentos restritas, dentre outras, - implicam em níveis de incerteza maiores, promovendo a maior preferência pela liquidez dos agentes econômicos, favorecendo os depósitos à vista e restringindo a disponibilidade de crédito, reduzindo, por conseguinte, o investimento. Os baixos níveis de investimentos retroalimentam o processo, tornando as regiões periféricas ainda mais vulneráveis e dependentes do centro.

Seguindo tal raciocínio, Rodriguez-Fuentes (1998) também destaca as diferenças nas preferências pela liquidez em regiões centrais e periféricas, em vista dos distintos níveis de incerteza, o que propicia padrões de disponibilidade de crédito mais instáveis nas regiões menos desenvolvidas. Assim, não há como considerar a atuação do sistema financeiro como um agente neutro no processo de desenvolvimento regional, já que pode resultar no aprofundamento dos indicadores de pobreza e das desigualdades entre as regiões.

Amparada nessas distintas perspectivas teóricas, a avaliação empírica reportada especialmente na última década demonstra a existência de correlação entre sistema financeiro, pobreza e a distribuição de renda. Estudos como os de Jalilian e Kirkpatrick (2002); Burgess e Pande (2005); Guillaumont e Kpodar (2005); Akhter e Daly (2009); Claessens e Feijen (2006); Clarke et al. (2003) e Beck et al. (2007) apresentam evidências empíricas de que a expansão do sistema financeiro contribui para a redução da pobreza absoluta e da desigualdade de renda, especialmente por possibilitar um crescimento mais rápido da renda dos pobres.

No caso brasileiro, a estabilização macroeconômica a partir de meados dos anos 1990, a reestruturação do sistema financeiro e a adoção de políticas públicas de promoção da renda durante as décadas seguintes são elementos de análise importantes pelos efeitos gerados na redução da pobreza e da desigualdade. Almeida e Jayme Jr. (2008), a partir de dados das 27 unidades da federação brasileiras, demonstram que a concentração bancária no Brasil no período 1995-2004 apresentou efeitos adversos sobre o crédito, considerando as evidências de que a presença de agências bancárias ou similares nas regiões do país mostrou-se positivamente correlacionada com a concessão de empréstimos, ao mesmo tempo em que a realocação e concentração do setor nas regiões mais desenvolvidas reduziram o estoque de crédito per capita em outras regiões. Na sequência do forte ajustamento do setor bancário verificou-se, também, maior racionamento do crédito, o que pode ser atribuído aos ganhos de poder de mercado obtidos com as fusões e consequente concentração. 
É fato que o Brasil buscou, particularmente a partir da década de 1990, criar instrumentos promotores do acesso ao sistema financeiro, até mesmo como condição necessária à estabilidade e solvência do setor, ao mesmo tempo em que o interesse por políticas públicas de redução da desigualdade e da pobreza tornava-se cada vez maior. Neste sentido, Kumar (2004) ressalta que, não obstante a concentração bancária verificada no país nas últimas décadas, a distribuição de serviços financeiros permaneceu constante. Isso pode ser atribuído, em certa medida, à expansão de novos pontos de serviços bancários, tais como caixas eletrônicos e correspondentes financeiros, assim como ao crescimento quantitativo de outros tipos de instituições financeiras, dentre as quais cooperativas e empresas voltadas para microfinanças. Resultados de análises econométricas realizadas pelo autor demonstram a tendência de uma relação positiva entre a renda per capita e indicadores de acesso ao sistema financeiro (como a densidade bancária) bem como a prestação de serviços de empréstimos e depósitos, o que corrobora a da análise de Almeida e Jayme Junior (2008).

Kumar (2004) sublinha ainda que os próprios diferenciais na renda e na densidade populacional, bem como os elementos inerentes à lógica da dinâmica do sistema financeiro podem, por seu turno, determinar a concentração da oferta dos serviços financeiros em áreas com níveis de rendimentos mais elevados, opinião consistente com as análises empíricas já realizadas sobre o caso do Brasil.

Ainda que incipiente no caso brasileiro, estudos como o de Bemerguy e Luporini (2006) e Bittencourt (2006) evidenciam que o desenvolvimento financeiro exerce impacto significativo sobre a taxa de crescimento da renda do segundo quintil mais pobre da população. Ademais, tais análises revelam ainda que o maior acesso ao crédito, especialmente pelas famílias pobres, exerce importante efeito sobre a redução da desigualdade de renda.

Alicerçadas nos princípios keynesianos de incerteza e preferência pela liquidez, e referenciadas na espacialidade, análises como as de Amado (1997; 2006); Barra e Crocco (2002); Crocco et al. (2003); Cavalcante et al. (2004; 2005) e Romero e Jayme Jr. (2009) demonstram que o efeito da moeda sobre o desempenho econômico das regiões brasileiras reflete uma dinâmica do tipo centro-periferia, favorecendo o processo de causação circular cumulativa, já que as regiões centrais têm maior capacidade de propiciar créditos quando comparadas às periféricas.

\section{Materiais e métodos}

\subsection{Descrição das variáveis}

Para inferir se o comportamento dos indicadores de pobreza e renda domiciliar per capita no Brasil, no período 1995-2008, foi influenciado por fatores monetários, relacionados ao desenvolvimento do sistema financeiro, foram 
utilizados três conjuntos de variáveis: i) as de interesse, ou seja, taxa de pobreza, renda domiciliar per capita média e renda domiciliar per capita média do pobre; ii) proxies para o desenvolvimento do sistema financeiro (apresentadas a seguir ; iii) as de controle, como índice de Gini, grau de informalidade, média de anos de estudos da população a partir de 25 anos de idade, taxa de desemprego e taxa de crescimento da renda domiciliar per capita média. A base de dados é anual e incluiu as 27 unidades federativas brasileiras, no período compreendido entre 1995-2008, totalizando 378 observações 5 .

Os indicadores do desenvolvimento do sistema financeiro seguem os padrões observados na literatura nacional e internacional considerando duas das dimensões propostas por Beck et al (2008), traduzidas no tamanho e na eficiência do setor. Além destas dimensões, foram incorporados, ainda, o acesso, a inclusão e as preferências pela liquidez do público e dos bancos, com o intuito de captar, com o maior grau de fidelidade possível, a multidimensionalidade do conceito de desenvolvimento do sistema financeiro.

O indicador "tamanho do setor financeiro" foi aferido pela relação passivo exigível (que compreende depósitos à vista e a prazo) e PIB (Produto Interno Bruto). Quanto maior este indicador, maior a intensidade e a capacidade do sistema financeiro em ofertar serviços e oportunidades de investimentos, gerando efeitos positivos sobre as taxas de crescimento da economia, emprego e renda. A proxy para medida de eficiência do setor financeiro é a razão crédito total/depósito total em relação ao PIB, expressando a ideia de que o sistema financeiro será mais eficiente de acordo com sua capacidade em transformar os depósitos captados em operações de crédito. Para aferir o grau de acesso da população brasileira aos serviços do sistema financeiro, adotou-se uma das medidas recomendadas pelo Banco Central do Brasil (2010), qual seja, o número médio de agências bancárias por 1.000 habitantes adultos (população a partir de 15 anos de idade). Como proxy para a inclusão financeira, foi empregada a relação depósitos totais/população adulta, comumente empregada pela literatura empírica. Cabe ressaltar que esta medida dá apenas uma ideia de um conceito muito mais amplo de inclusão financeira, que envolve a possibilidade de uso efetivo por parte da população dos diversos serviços e produtos do sistema financeiro, abrangendo depósitos, operações de crédito, dentre outros.

Conforme Dow (1982), a preferência pela liquidez tem papel fundamental na oferta de crédito. A concepção de preferência pela liquidez apóia-se no comportamento dos agentes econômicos em relação à alocação dos seus ativos, em um ambiente caracterizado pela incerteza. Assim, quanto menor o nível de confiança e quanto maior a incerteza em relação ao retorno de investimentos, maior a

(5) Fontes dos dados no item 2.2. 
preferência dos agentes por ativos mais líquidos, sendo menor a disponibilidade de crédito, o que afeta negativamente o desempenho da atividade macroeconômica, implicando no aumento da pobreza. A literatura empírica ${ }^{6}$ em geral emprega a razão depósitos à vista/depósitos totais como medida do índice de preferência pela liquidez do público, uma vez que os depósitos à vista representam a propensão do público por ativos mais líquidos. É importante sublinhar que, conforme ponderam Crocco et al. (2006, p. 304), esta medida é suscetível de questionamentos em função dos depósitos à vista não traduzirem, integralmente, a preferência pela liquidez do público, já que alguns tipos de depósitos a prazo podem, também, apresentarem liquidez elevada. Contudo, a construção de um indicador mais acurado é impossibilitada, dada a restrição imposta pela inexistência de uma base de dados adequada. Por outro lado, a razão depósitos à vista/operações de crédito é comumente utilizada como indicador de preferência pela liquidez dos bancos.

Como variáveis de resposta foram consideradas a taxa de pobreza, a renda domiciliar per capita média e a renda domiciliar per capita média do pobre, com o intuito de apreender se o desenvolvimento do sistema financeiro afeta a proporção de indivíduos considerados pobres, bem como inferir possíveis impactos diferenciados nos dois tipos de rendimentos sob consideração. A taxa de pobreza, segundo o conceito do Instituto de Pesquisas Econômicas Aplicadas (Ipea), corresponde ao percentual de pessoas na população total com renda domiciliar per capita média inferior à linha de pobreza, sendo calculada como o dobro da linha de extrema pobreza ${ }^{7}$. A renda domiciliar per capita média do pobre corresponde à razão entre o somatório da renda per capita de todos os indivíduos considerados pobres e o número total desses indivíduos, tendo como referência a linha de pobreza.

Com o intuito de controlar os efeitos de variáveis que são passíveis de impactar a pobreza e a renda, captando os efeitos puros das variáveis de interesse e minimizando a possibilidade de viés nas estimativas, foram utilizadas variáveis de controle conforme descrito a seguir. Para captar os efeitos da educação sobre as variáveis de interesse, utilizou-se a média de anos de estudos, equivalente à razão entre o somatório de anos de estudos completados pelas pessoas a partir de 25 anos de idade e o total de pessoas nesta faixa etária. Considerando que a desigualdade de renda é, comprovadamente, um dos determinantes da pobreza e uma característica marcante entre os Estados brasileiros, o controle para este efeito foi feito por meio

(6) Como em Crocco et al. (2003) e Cavalcante et al. (2005), dentre outros.

(7) Segundo o Ipea, a estimativa da linha de extrema pobreza leva em conta o custo de uma cesta básica de alimentos, que contenha o mínimo de calorias necessárias para atender, de forma adequada, uma pessoa, tendo em vista as recomendações da Food and Agricultural Organization - FAO, das Nações Unidas, bem como da Organização Mundial da Saúde - OMS. Estes custos são estimados considerando as disparidades nos padrões de consumo das regiões brasileiras. 
do índice de Gini. Para controlar os efeitos do setor informal ${ }^{8}$ sobre as taxas de pobreza e renda domiciliar per capita, foi utilizado o grau de informalidade, adotado pelo Ipea, que resulta da seguinte razão: trabalhadores sem carteira mais trabalhadores por conta própria, dividido pelos trabalhadores protegidos (com carteira), empregados sem carteira, trabalhadores por conta própria e os empregadores. A taxa de desemprego, definida como o percentual de pessoas a partir de 10 anos de idade que procuraram e não encontraram ocupação profissional remunerada na semana de referência da Pesquisa Nacional por Amostras de Domicílios - PNAD, controla os efeitos dos ciclos econômicos sobre a taxa de pobreza e a renda domiciliar per capita. Considerando que variações na taxa de crescimento da renda domiciliar per capita média dependem, primordialmente, do nível de atividade da economia e, via efeito multiplicador, provocam mudanças na trajetória dos indicadores de pobreza, a depender do grau de concentração da renda, buscou-se controlar os possíveis defeitos dessa variável sobre o comportamento da taxa de pobreza.

\subsection{Fonte dos dados}

Os dados utilizados para a construção dos indicadores de desenvolvimento do sistema financeiro, quais sejam, depósitos à vista e a prazo, depósitos totais, operações de crédito (todos a preços correntes) e agências processadas foram obtidos junto ao Laboratório de Estudos em Moeda e Território - LEMTe, do Centro de Planejamento e Desenvolvimento Regional - Cedeplar, da Universidade Federal de Minas Gerais - UFMG, tendo como fonte primordial a Estatística Bancária Mensal do Banco Central do Brasil - Bacen.

Os dados das variáveis de interesse e de controle relativos à taxa de pobreza, renda domiciliar per capita média, renda domiciliar per capita média do pobre, índice de Gini, grau de informalidade, média de anos de estudos da população a partir de 25 anos e taxa de desemprego foram extraídos das séries estatísticas constantes da base Ipeadata, calculadas pelo Instituto Ipea, a partir da Pesquisa Nacional por Amostras de Domicílio - Pnad. Esta mesma fonte foi, também, utilizada para a obtenção do produto interno PIB a preços correntes, com dados oriundos do Sistema de Contas Regionais do Instituto Brasileiro de Geografia e Estatística - IBGE. As estimativas da população foram obtidas do arquivo Brasil, Grandes Regiões e Unidades da Federação: Estimativas da população com data de referência em primeiro de julho de cada ano: 1980/2031 do IBGE.

(8) Por considerar que renda e pobreza vinculam-se fortemente aos níveis de desemprego e de informalidade existentes. Trabalhadores que atuam no setor informal estão sujeitos a rendimentos e proteção menores sendo, portanto, mais vulneráveis às oscilações no crescimento econômico.

(9) Os dados de renda domiciliar per capita média são a preços constantes de outubro de 2006. 
Importante mencionar que foi necessária a interpolação de dados para o ano de 2000, por meio da média dos primeiros anos adjacentes (anterior e posterior) daquelas variáveis não disponibilizadas pela PNAD que não foi a campo naquele ano.

\subsection{Modelo empírico}

Uma das dificuldades de investigar correlações entre variáveis como as aqui consideradas é encontrar medidas únicas que sejam capazes de traduzir fielmente o nível de desenvolvimento financeiro e da pobreza, face aos traços característicos de multidimensionalidade subjacentes a ambos os conceitos. Para além da definição convencional de privação de renda, mais amplamente utilizada nas análises empíricas, a pobreza compreende também muitas outras dimensões, dentre as quais podemos identificar a desigualdade da distribuição da renda, a educação e o emprego. Da mesma forma, um dos principais desafios enfrentados pela literatura empírica relacionada ao tema objeto deste estudo é encontrar indicadores padronizados e consensuais capazes de traduzir adequadamente o grau ou intensidade do desenvolvimento financeiro, geralmente definidos como a melhoria na quantidade, qualidade e eficiência dos produtos do setor. Assim, dadas as características das variáveis consideradas relevantes para a análise da relação entre o desenvolvimento do sistema financeiro e dos indicadores de renda e pobreza no Brasil, optou-se pela utilização do método multivariado de análise da correlação canônica, que possibilita medir o grau de associação entre dois conjuntos de múltiplas variáveis dependentes e independentes.

A vantagem desse tipo de metodologia em relação às demais técnicas econométricas é que ela reflete de forma mais acurada o caráter multidimensional da realidade, já que permite investigar conjuntos de variáveis que envolvem múltiplas causas e efeitos que, na verdade, caracterizam a complexidade e diversidade subjacente à pobreza e ao desenvolvimento do sistema financeiro, além de, em certa medida, captar os aspectos relacionados à causalidade reversa. Nesse sentido, Thompson (1991) ressalta que as análises multivariadas, especialmente a correlação canônica, podem gerar resultados que poderiam não ser captados, quando são empregados métodos univariados. Apenas no contexto de uma perspectiva analítica multivariada é possível considerar, simultaneamente, as diversas dimensões das interações entre as variáveis, o que torna a análise mais próxima da realidade.

É importante destacar que para dados estruturados por unidades da federação ao longo do tempo, utiliza-se, também, a técnica de dados em painel, que permite explorar a variabilidade tanto do ponto de vista da dimensão temporal, quanto espacial ou das unidades de análise. Embora dados em painel seja uma técnica que vem sendo empregada com frequência em estudos que relacionam o desenvolvimento do sistema financeiro e o crescimento econômico, a opção pela 
análise da correlação canônica, em um primeiro momento, deve-se ao seu ineditismo neste tipo de estudo, assim como à sua adequabilidade à base de dados analisada. Pretende-se, em sequência, realizar uma análise com a mesma base de dados, utilizando a técnica de painel, comparando, inclusive, os resultados obtidos das duas metodologias, o que extrapolaria o tamanho requerido para o texto.

Dessa forma e em um sentido amplo, a análise da correlação canônica avalia como o conjunto de variáveis relativas ao desenvolvimento do sistema financeiro se relaciona com o conjunto de variáveis correlatas à pobreza e à renda no Brasil, no período compreendido entre 1995-2008. De forma mais estrita, buscou-se: i) determinar a magnitude das relações existentes entre os conjuntos de variáveis do desenvolvimento do sistema financeiro, pobreza e renda; ii) avaliar a importância ou contribuição relativa de cada variável na relação entre desenvolvimento do sistema financeiro, pobreza e renda; iii) examinar a natureza da relação entre os conjuntos de variáveis de interesse do estudo.

Ressalte-se que as restrições impostas pela base de dados desagregados para as unidades federativas brasileiras, especialmente no que se refere aos indicadores do sistema financeiro, disponíveis apenas a partir de 1994, foram determinantes para a delimitação do período de estudo, impossibilitando, dessa forma, a comparação entre os períodos pré e pós-estabilização da economia brasileira.

O modelo estrutural básico considerado adequado para a análise empírica foi conformado com base em uma função canônica representativa da correlação linear entre dois conjuntos de variáveis - denominadas variáveis estatísticas canônicas expressas por duas composições lineares distintas: uma para as variáveis dependentes e outra para as variáveis independentes, observando a seguinte especificação:

ltamanho+leficiencia+acesso+inclusao+liquipublico+liquibanco=taxapobreza

gini + desemprego + informal + anosestudo $=$ taxarendapc

A combinação linear entre os conjuntos compostos de variáveis relativas ao desenvolvimento do sistema financeiro e o formado por variáveis correlacionadas com a pobreza, produz seis pares de funções canônicas, ou seja, de $U_{1}$ e $V_{1}$ a $U_{6}$ e $\mathrm{V}_{6}$, conforme configurado nas seguintes equações:

$U_{1}=\alpha_{1} l$ tamanho $+\alpha_{2}$ leficiencia $+\alpha_{3}$ acesso $+\alpha_{4}$ inclusao $+\alpha_{5}$ liquipublico $+\alpha_{6} l i q u i b a n c o$

$V_{l=} \beta_{1}$ taxapobreza+ $\beta_{2}$ gini $_{+} \beta_{3}$ desemprego ${ }_{+} \beta_{4}$ anosestudo $\beta_{+} \beta_{5 \text { informal }} \beta_{6}$ taxarendapc

$U_{6}=\alpha_{1}$ ltamanho $+\alpha_{2}$ leficiencia $+\alpha_{3}$ acesso $+\alpha_{4}$ inclusao $+\alpha_{5}$ liquipublico $+\alpha_{6}$ liquibanco

$V 6=\beta_{1}$ taxapobreza $+\beta_{2}$ gini $+\beta_{3}$ desemprego $+\beta_{4}$ anosestudo $+\beta_{5}$ informal $+\beta_{6}$ taxarendapc

Economia e Sociedade, Campinas, v. 25, n. 1 (56), p. 247-278, abr. 2016. 
em que $\mathrm{U}_{1}$ a $\mathrm{U}_{6}$ são funções canônicas compostas pelas variáveis correlacionadas com o desenvolvimento do sistema financeiro; $\mathrm{V}_{1}$ a $\mathrm{V}_{6}$ são funções canônicas formadas pelas variáveis correlacionadas com a pobreza; ltamanho, leficiência, acesso, inclusão, liquipublico, liquibanco são variáveis proxies já descritas para, respectivamente, o tamanho, a eficiência do sistema financeiro, o grau de acesso da população aos serviços financeiros, a inclusão financeira da população, a preferência pela liquidez do público e a preferência pela liquidez dos bancos. Neste mesmo sentido, taxapobreza, gini, desemprego, anosestudo, informal e taxarendapc são, respectivamente, indicadores da taxa de pobreza, do índice de desigualdade de Gini, da taxa de desemprego, do grau de informalidade, da média de anos de estudos da população de 25 anos e mais, da taxa de crescimento real da renda domiciliar per capita média; enquanto $\alpha e \beta$ são os parâmetros a serem estimados.

O primeiro par de variáveis estatísticas canônicas $\left(\mathrm{U}_{1}, \mathrm{~V}_{1}\right)$ é computado de forma a obter a máxima correlação possível entre os conjuntos de variáveis relacionados ao sistema financeiro e a pobreza. $\mathrm{O}$ segundo par exibe a maior correlação possível entre ambos os conjuntos de variáveis canônicas que não foram explicadas pelo primeiro par. Dessa forma, os pares sucessivos de variáveis estatísticas canônicas são derivados da variância residual não computada pelas funções precedentes, o que determina que as correlações canônicas tornam-se menores a cada função canônica adicional. Isto implica, ainda, que cada par de variáveis estatísticas canônicas seja ortogonal e independente das demais variáveis estatísticas obtidas a partir do mesmo conjunto de dados. (Hair et al., 1998)

A expectativa subjacente ao modelo correspondente à equação (1) é a de que o conjunto de múltiplas variáveis correlacionadas com a pobreza apresente covariância com o conjunto de múltiplas variáveis do desenvolvimento do sistema financeiro em um sentido inverso. Intuitivamente, isso significa dizer que o desenvolvimento do sistema financeiro é responsável por parte da variância do composto relativo à pobreza, podendo a análise em sentido oposto ser, também, verdadeira. Excetuam-se as variáveis de preferências pela liquidez que devem covariar com as variáveis relacionadas com a pobreza em um sentido direto, indicando que o aumento nas preferências pela liquidez do público e dos bancos tem um efeito de crescimento da taxa de pobreza, seguindo os pressupostos da teoria póskeynesiana.

Para avaliar os efeitos do desenvolvimento do sistema financeiro sobre a renda, duas especificações do modelo foram formalizadas a partir da equação (1), substituindo a taxa de pobreza (taxapobreza) pela renda domiciliar per capita média (lrendapc) e pela renda domiciliar per capita média da população pobre (lrendapcpobre), bem como excluindo a taxa de crescimento da renda domiciliar per capita média, o que resultou nas seguintes equações: 
ltamanho + leficiencia + acesso + inclusao + liquipublico + liquibanco $=$ lrendapc

Gini+desemprego+informal+anosestudo

ltamanho+leficiencia+acesso+inclusao+liquipublico+liquibanco=lrendapcpobre

gini+desemprego+informal+anosestudo

Espera-se, com os modelos representados pelas equações (6) e (7), que o conjunto de variáveis correlacionado com a renda domiciliar per capita medida e com a renda domiciliar per capita média do pobre apresente uma covariância positiva com o conjunto de variáveis correlacionadas com o desenvolvimento do sistema financeiro, mantendo a exceção para as variáveis relativas à preferência pela liquidez, que devem apresentar covariância no sentido inverso ao crescimento da renda.

\section{Análise dos resultados}

\subsection{Significância estatística das correlações canônicas}

Para o conjunto de variáveis de interesse, relacionado com a pobreza, a análise da correlação canônica resultou na determinação de seis variáveis canônicas, ou seja, o mesmo número de variáveis do conjunto dependente. Conforme consta da Tabela 1, os testes de significância multivariados, fundamentados no Lambda de Wilks, no critério de Pillai, no Traço de Hotelling e no Gcr de Roy comprovaram que, quando avaliadas conjuntamente, todas as funções canônicas foram significantes a $1 \%$.

Tabela 1

Testes de significância multivariados

\begin{tabular}{lccc}
\hline \multicolumn{4}{c}{ Variáveis correlacionadas com a Pobreza } \\
\hline \multicolumn{1}{c}{ Teste } & Estatística & Estatística F Aproximada & Probabilidade \\
\hline Lambda de Wilks & 0,0711 & 36,9292 & 0,0000 \\
\hline Traço de Pillai & 1,6615 & 24,6139 & 0,0000 \\
\hline Traço de Hotelling & 4,5056 & 48,2422 & 0,0000 \\
\hline Gcr de Roy & 3,0124 & 191,6637 & 0,0000 \\
\hline \multicolumn{4}{c}{ Variáveis correlacionadas com a Renda Domiciliar per capita média } \\
\hline Lambda de Wilks & 0,0692 & 46,5041 & 0,0000 \\
\hline Traço de Pillai & 1,7229 & 32,5082 & 0,0000 \\
\hline Traço de Hotelling & 4,8948 & 59,6191 & 0,0000 \\
\hline Gcr de Roy & 3,3286 & 205,8215 & 0,0000 \\
\hline \multicolumn{1}{c}{ Variáveis correlacionadas com a Renda Domiciliar per capita média do Pobre } \\
\hline Lambda de Wilks & 0,106777 & 36,7189 & 0,0000 \\
\hline Traço de Pillai & 1,48995 & 26,2470 & 0,0000 \\
\hline Traço de Hotelling & 3,86416 & 47,0655 & 0,0000 \\
\hline Gcr de Roy & 2,71976 & 168,1716 & 0,0000 \\
\hline
\end{tabular}

Fonte: Elaboração própria. 
Para os conjuntos relacionados à renda domiciliar per capita média e renda domiciliar per capita média dos pobres, os resultados da estimação geraram cinco variáveis canônicas, já que foi excluída uma variável, a taxa de crescimento da renda. Os testes multivariados obtidos foram similares aos do conjunto correlacionado com a pobreza, demonstrando, também, significância estatística ao nível de $1 \%$.

Resultados similares foram também obtidos a partir dos testes específicos para cada função canônica, baseados no Lambda de Wilks, que demonstram a significância estatística ao nível de $1 \%$ das quatro primeiras dimensões canônicas das variáveis correlacionadas com a pobreza, conforme descrito na Tabela 2. As quintas e sextas dimensões canônicas demonstraram significância estatística aos níveis $5 \%$ e $10 \%$, respectivamente.

Nos testes individualizados para o conjunto de variáveis correlacionado com a renda domiciliar per capita média, as quatro primeiras dimensões demonstraram significância em nível de $1 \%$, enquanto a quinta apresentou significância no nível de $5 \%$. Para o conjunto correlacionado com a renda domiciliar per capita média do pobre, as três primeiras dimensões apresentaram significância estatística em nível de $1 \%$, enquanto a quarta dimensão foi significativa no nível $5 \%$ e a quinta dimensão não demonstrou significância (Prob $>\mathrm{F}=0,8143$ ). Tais resultados confirmam a hipótese de existência de correlação entre o conjunto de variáveis representativas do sistema financeiro e o conjunto de variáveis relativas à pobreza, à renda domiciliar per capita média e à renda domiciliar per capita média do pobre.

\subsection{Magnitude das correlações canônicas}

Uma vez constatada a existência de relação linear entre os conjuntos de variáveis do desenvolvimento do sistema financeiro, da pobreza e das rendas per capita, é importante avaliar a correlação canônica, a qual mede a força de associação entre os dois conjuntos de variáveis, ou o grau com que eles são linearmente correlacionados. As raízes canônicas $\left(\mathrm{R}^{2}\right)$, também conhecidas como autovalores, mostram a variância compartilhada entre os conjuntos de variáveis considerados dependentes e explicativos.

Os resultados da Tabela 2 demonstram que a primeira função canônica, do conjunto de variáveis relacionado à pobreza, apresentou um maior grau de correlação $(0,8695)$, com uma raiz canônica $\left(\mathrm{R}^{2}\right)$ correspondente a 0,7560 , o que indica a quantidade de variância linearmente compartilhada entre os dois conjuntos de variáveis. Isso significa que a variável canônica independente, desenvolvimento do sistema financeiro, compartilha 75,6\% da variância da variável canônica dependente, pobreza. Similarmente, a variável canônica relacionada à pobreza também compartilha do mesmo percentual da variância da variável canônica do desenvolvimento do sistema financeiro. 
Tabela 2

Medidas de ajuste geral dos modelos

\begin{tabular}{c|ccccc}
\hline \multicolumn{5}{c}{ Variáveis correlacionadas com a Pobreza } \\
\hline $\begin{array}{c}\text { Função } \\
\text { Canônica }\end{array}$ & $\begin{array}{c}\text { Correlação } \\
\text { Canônica }\end{array}$ & $\begin{array}{c}\text { Raiz Canônica } \\
\mathrm{R}^{2}\end{array}$ & Estatística F & Probabilidade \\
\hline 1 & 0,8695 & 0,7560 & 36,9292 & 0,0000 \\
\hline 2 & 0,7223 & 0,5217 & 21,4823 & 0,0000 \\
\hline 3 & 0,5537 & 0,3065 & 12,3704 & 0,0000 \\
\hline 4 & 0,3073 & 0,0944 & 5,4342 & 0,0000 \\
\hline 5 & 0,1413 & 0,0199 & 2,7806 & 0,0260 \\
\hline 6 & 0,0980 & 0,0096 & 3,6007 & 0,0585 \\
\hline \multicolumn{5}{c}{ Variáveis correlacionadas com a Renda Domiciliar per capita média } \\
\hline 1 & 0,8769 & 0,7689 & 46,5041 & 0,0000 \\
\hline 2 & 0,6826 & 0,4659 & 26,7333 & 0,0000 \\
\hline 3 & 0,5929 & 0,3515 & 19,8282 & 0,0000 \\
\hline 4 & 0,3377 & 0,1140 & 9,1905 & 0,0000 \\
\hline 5 & 0,1496 & 0,0223 & 4,2469 & 0,0150 \\
\hline \multicolumn{7}{c}{ Variávein correlacionadas com a Renda Domiciliar per capita média do Pobre } \\
\hline 1 & 0,8551 & 0,7311 & 36,189 & 0,0000 \\
\hline 2 & 0,6229 & 0,3880 & 19,6056 & 0,0000 \\
\hline 3 & 0,5535 & 0,3063 & 14,4437 & 0,0000 \\
\hline 4 & 0,2516 & 0,0633 & 4,1691 & 0,0004 \\
\hline 5 & 0,0333 & 0,0011 & 0,2055 & 0,8143 \\
\hline
\end{tabular}

Fonte: Elaboração própria.

Para as segunda e terceira dimensões canônicas, os $\mathrm{R}^{2}$ obtidos são, também, expressivos, ou seja, de 0,5217 e 0,3065, respectivamente. As dimensões canônicas quatro e cinco, mesmo demonstrando significância estatística, apresentaram um baixo grau de correlação, com $\mathrm{R}^{2}$ menores que 0,10 . A dimensão seis, além de não apresentar significância estatística ao nível de $5 \%$, exibe um $\mathrm{R}^{2}$ também menor do que $10 \%$.

Levando em consideração as correlações canônicas dos conjuntos renda domiciliar per capita média e renda domiciliar per capita média do pobre, pode-se observar resultados similares ao conjunto da pobreza. Para a renda domiciliar per capita média, a primeira dimensão apresentou correlação canônica $(0,8769)$ e $\mathrm{R}^{2}$ $(0,7689)$ muito próximos àquelas obtidas para o conjunto relacionado à pobreza $(0,8695$ e 0,7560 , respectivamente $)$, o que pode ser justificado pelas similaridades na composição de ambos os conjuntos. As segundas e terceiras dimensões exibem, da mesma forma, raízes canônicas bastante aceitáveis, de 0,4639 e 0,3515, respectivamente. As quartas e quintas dimensões mostraram fraca variância compartilhada pelos dois conjuntos de variáveis canônicas $(0,1140$ e 0,0223$)$. Comportamento idêntico foi mostrado pelos resultados obtidos com a variável relacionada à renda domiciliar per capita média do pobre, com as três primeiras 
dimensões apresentando uma boa variância compartilhada e as duas últimas dimensões exibindo baixas raízes canônicas.

Em síntese, a maioria das dimensões canônicas demonstrou significância estatística, quer seja para as variáveis relacionadas à pobreza, à renda domiciliar per capita média ou à renda domiciliar per capita média do pobre, o que confirma a hipótese de correlação com o conjunto de variáveis do desenvolvimento do sistema financeiro. Não obstante, em todos os casos, as raízes canônicas $\left(\mathrm{R}^{2}\right)$ só apresentaram uma boa variância compartilhada até a terceira dimensão. Ademais, importa ponderar que apenas uma alta correlação canônica não é suficiente para que a relação linear entre as variáveis seja validada, o que requer outros indicadores que possam ser capazes de confirmar a predição.

\section{3 Índice de redundância}

O índice de redundância fornece uma medida mais realista da capacidade de predição da função canônica, indicando se existe uma significância prática na explicação da variância da variável canônica dependente. Nessa perspectiva, o índice de redundância da variável estatística dependente representa a quantidade de variância nas variáveis dependentes explicada pela variável canônica independente. Esta estatística é obtida ao mensurar o produto do quadrado das cargas canônicas médias e da raiz canônica $\left(\mathrm{R}^{2}\right)$. Pela Tabela 3 , pode-se inferir que, aproximadamente, $35 \%$ da variância nas variáveis dependentes, referentes à pobreza, pode ser atribuída à variabilidade do conjunto relativo ao desenvolvimento do sistema financeiro, quando considerada a primeira variável canônica.

Para a segunda dimensão, os resultados apresentaram pouco poder explicativo, tanto para a variável canônica relativa à pobreza $(0,0495)$, quanto para a relativa ao desenvolvimento do sistema financeiro $(0,0607)$, o que deve ser atribuído à menor carga canônica ao quadrado médio ou variância compartilhada de cada variável, bem como a uma raiz canônica menor. Ainda que a segunda variável canônica tenha apresentado significância estatística, conforme evidenciado pelos testes multivariados constantes da Tabela 1, ela não apresentou significância prática, uma vez que as variáveis relacionadas ao desenvolvimento do sistema financeiro não demonstraram um bom poder de predição da maior parte da variância da variável canônica relativa à pobreza. Vale registrar que cada dimensão canônica representa, necessariamente, relações específicas entre os conjuntos de variáveis dependentes e independentes, de tal forma a manter entre si os pressupostos de independência e ortogonalidade. Nesse sentido, a primeira variável canônica não apresenta covariância com a segunda, o mesmo acontecendo entre as demais. 
Tabela 3

Índice de redundância - Variável canônica relativa à pobreza

\begin{tabular}{|c|c|c|c|c|c|}
\hline \multicolumn{6}{|c|}{ Primeira Variável Canônica } \\
\hline Variável & $\begin{array}{c}\text { Carga } \\
\text { Canônica }\end{array}$ & $\begin{array}{c}\text { Carga } \\
\text { Canônica } \\
\text { ao quadrado }\end{array}$ & $\begin{array}{c}\text { Carga Canônica } \\
\text { ao quadrado } \\
\text { Média }\end{array}$ & $\mathrm{R}^{2}$ Canônico & $\begin{array}{c}\text { Índice de } \\
\text { Redundância }\end{array}$ \\
\hline \multicolumn{6}{|c|}{0,0685} \\
\hline \multicolumn{6}{|l|}{ leficiência } \\
\hline \multicolumn{6}{|c|}{0,7567} \\
\hline inclusão & $-0,5869$ & \multicolumn{4}{|l|}{0,3444} \\
\hline liquipublico & 0,1340 & \multicolumn{4}{|l|}{0,0179} \\
\hline liquibanco & 0,1649 & \multicolumn{4}{|l|}{0,0272} \\
\hline \multicolumn{3}{|c|}{ Desenvolvimento do Sistema Financeiro } & 0,2472 & 0,7560 & 0,1869 \\
\hline taxapobreza & 0,9765 & \multicolumn{4}{|l|}{0,9535} \\
\hline gini & 0,4926 & \multicolumn{4}{|l|}{0,2426} \\
\hline desemprego & 0,0037 & \multicolumn{4}{|l|}{0,0000} \\
\hline informal & 0,9176 & \multicolumn{4}{|l|}{0,8419} \\
\hline anosestudo & $-0,8445$ & \multicolumn{4}{|l|}{0,7131} \\
\hline taxarendapc & $-0,0739$ & \multicolumn{4}{|l|}{0,0054} \\
\hline Pobreza & & & 0,4594 & 0,7560 & 0,3473 \\
\hline \multicolumn{6}{|c|}{ Segunda Variável Canônica } \\
\hline ltamnaho & 0,1959 & \multicolumn{4}{|c|}{0,0383} \\
\hline leficiência & $-0,1809$ & \multicolumn{4}{|l|}{0,0327} \\
\hline acesso & $-0,2996$ & \multicolumn{4}{|l|}{0,0897} \\
\hline inclusão & 0,6335 & \multicolumn{4}{|l|}{0,4013} \\
\hline liquipublico & $-0,1537$ & \multicolumn{4}{|l|}{0,0236} \\
\hline liquibanco & 0,3360 & \multicolumn{4}{|l|}{0,1128} \\
\hline \multicolumn{3}{|c|}{ Desenvolvimento do Sistema Financeiro } & 0,1164 & 0,5217 & 0,0607 \\
\hline taxapobreza & 0,1633 & 0,0267 & & & \\
\hline gini & 0,2286 & 0,0522 & & & \\
\hline desemprego & 0,4905 & 0,2405 & & & \\
\hline informal & $-0,1239$ & 0,0153 & & & \\
\hline anosestudo & 0,4842 & 0,2344 & & & \\
\hline taxarendapc & 0,0188 & 0,0003 & & & \\
\hline Pobreza & & & 0,0949 & 0,5217 & 0,04950 \\
\hline
\end{tabular}

Fonte: Elaboração própria.

Conforme a Tabela 4, o índice de redundância obtido para a variável correlata à renda domiciliar per capita média, em sua primeira dimensão, é mais expressivo $(0,4123)$ do que o verificado para a variável canônica relacionada à pobreza $(0,3473)$, o que significa que o desenvolvimento do sistema financeiro traduz mais fortemente a variância na renda per capita média do que na taxa de pobreza. Considerando que os compostos de variáveis relacionadas à pobreza e à renda são similares, diferindo exatamente por estas duas variáveis, estes resultados são sugestivos de que o desenvolvimento do sistema financeiro impacta mais fortemente a renda domiciliar per capita média. Se por um lado isso pode significar o efeito positivo que o desenvolvimento do sistema financeiro gera no crescimento 
econômico, repercutindo favoravelmente sobre a renda, por outro, pode, também, sinalizar que o menor efeito sobre a redução na taxa de pobreza seja indicativo das desigualdades na distribuição da renda, o que parece coerente com a realidade da economia brasileira nos anos 2000.

Seguindo o mesmo comportamento verificado para a taxa de pobreza, a segunda dimensão canônica também evidenciou uma fraca variância - traduzida em um índice de redundância de 0,0514 - entre as variáveis canônicas, quando a composição relacionada à renda domiciliar per capita média foi considerada como variável dependente.

Tabela 4

Índice de redundância

Variável canônica relativa à renda domiciliar per capita média

\begin{tabular}{|c|c|c|c|c|c|}
\hline \multicolumn{6}{|c|}{ Primeira Variável Canônica } \\
\hline Variável & $\begin{array}{c}\text { Carga } \\
\text { Canônica }\end{array}$ & $\begin{array}{c}\text { Carga } \\
\text { Canônica } \\
\text { ao quadrado }\end{array}$ & $\begin{array}{c}\text { Carga } \\
\text { Canônica ao } \\
\text { quadrado } \\
\text { Média }\end{array}$ & $\mathrm{R}^{2}$ Canônico & $\begin{array}{c}\text { Índice de } \\
\text { Redundância }\end{array}$ \\
\hline \multicolumn{6}{|c|}{0,1706} \\
\hline leficiência & $-0,4630$ & \multicolumn{4}{|l|}{0,2143} \\
\hline acesso & 0,8768 & \multicolumn{4}{|l|}{0,7687} \\
\hline inclusão & 0,7055 & \multicolumn{4}{|l|}{0,4977} \\
\hline liquipublico & $-0,2097$ & \multicolumn{4}{|l|}{0,0439} \\
\hline liquibanco & $-0,2100$ & \multicolumn{4}{|l|}{0,0441} \\
\hline \multicolumn{3}{|c|}{ Desenvolvimento do Sistema Financeiro } & 0,2899 & 0,7689 & 0,2229 \\
\hline lrendapc & 0,9953 & \multicolumn{4}{|l|}{0,9535} \\
\hline gini & $-0,3887$ & \multicolumn{4}{|l|}{0,2426} \\
\hline desemprego & 0,0216 & \multicolumn{4}{|l|}{0,0000} \\
\hline informal & $-0,9152$ & \multicolumn{4}{|l|}{0,8419} \\
\hline anosestudo & 0,8375 & \multicolumn{4}{|l|}{0,7131} \\
\hline \multicolumn{3}{|c|}{ Renda Domiciliar per capita média } & 0,5362 & 0,7689 & 0,4123 \\
\hline \multicolumn{6}{|c|}{ Segunda Variável Canônica } \\
\hline ltamanho & 0,3143 & \multicolumn{4}{|l|}{0,0987} \\
\hline leficiência & 0,3424 & \multicolumn{4}{|l|}{0,1172} \\
\hline acesso & 0,4205 & \multicolumn{4}{|l|}{0,1768} \\
\hline inclusão & $-0,2715$ & \multicolumn{4}{|l|}{0,0737} \\
\hline liquipublico & $-0,1881$ & \multicolumn{4}{|l|}{0,0353} \\
\hline liquibanco & $-0,5954$ & \multicolumn{4}{|l|}{0,3545} \\
\hline \multicolumn{3}{|c|}{ Desenvolvimento do Sistema Financeiro } & 0,1427 & 0,5217 & 0,0665 \\
\hline lrendapc & 0,0156 & \multicolumn{4}{|l|}{0,0002} \\
\hline gini & 0,1691 & \multicolumn{4}{|l|}{0,0285} \\
\hline desemprego & $-0,4782$ & \multicolumn{4}{|l|}{0,2286} \\
\hline informal & $-0,0628$ & \multicolumn{4}{|l|}{0,0039} \\
\hline anosestudo & 0,5393 & \multicolumn{4}{|l|}{0,2908} \\
\hline \multicolumn{3}{|c|}{ Renda Domiciliar per capita média } & 0,1104 & 0,5217 & 0,0514 \\
\hline
\end{tabular}

Fonte: Elaboração própria. 
No caso da renda domiciliar per capita média do pobre, o índice de redundância para a primeira variável canônica foi menos expressivo $(0,2767)$, conforme resultados apresentados na Tabela 5. Não obstante, levando-se em conta

Tabela 5

Índice de Redundância

Variável canônica relativa à renda domiciliar per capita média do pobre

\begin{tabular}{|c|c|c|c|c|c|}
\hline \multicolumn{6}{|c|}{ Primeira Variável Canônica } \\
\hline Variável & $\begin{array}{c}\text { Carga } \\
\text { Canônica }\end{array}$ & $\begin{array}{c}\text { Carga } \\
\text { Canônica } \\
\text { ao quadrado }\end{array}$ & $\begin{array}{l}\text { Carga Canônica } \\
\text { ao quadrado } \\
\text { Média }\end{array}$ & $\mathrm{R}^{2}$ Canônico & $\begin{array}{c}\text { Índice de } \\
\text { Redundância }\end{array}$ \\
\hline ltamanho & \multicolumn{5}{|c|}{$0,2800 \quad 0,0784$} \\
\hline leficiência & $-0,5439$ & \multicolumn{4}{|l|}{0,2958} \\
\hline acesso & 0,7821 & \multicolumn{4}{|l|}{0,6116} \\
\hline inclusão & 0,7044 & \multicolumn{4}{|l|}{0,4961} \\
\hline liquipublico & $-0,1734$ & \multicolumn{4}{|l|}{0,0300} \\
\hline liquibanco & $-0,0803$ & \multicolumn{4}{|l|}{0,0064} \\
\hline \multicolumn{3}{|c|}{ Desenvolvimento do Sistema Financeiro } & 0,2531 & 0,7311 & 0,1850 \\
\hline lrendapcpobre & 0,5728 & \multicolumn{4}{|l|}{0,3280} \\
\hline gini & $-0,4488$ & \multicolumn{4}{|l|}{0,2014} \\
\hline desemprego & 0,0871 & \multicolumn{4}{|l|}{0,0075} \\
\hline informal & $-0,9346$ & \multicolumn{4}{|l|}{0,8734} \\
\hline anosestudo & 0,9279 & \multicolumn{4}{|l|}{0,8609} \\
\hline \multirow{2}{*}{\multicolumn{6}{|c|}{ Renda Domiciliar per capita média pobre $\quad 0,3785$}} \\
\hline \multicolumn{3}{|c|}{ Segunda Variável Canônica } & & & \\
\hline ltamanho & 0,2018 & \multicolumn{4}{|c|}{0,0407} \\
\hline leficiência & 0,0068 & \multicolumn{4}{|l|}{0,0000} \\
\hline acesso & 0,4874 & \multicolumn{4}{|l|}{0,2375} \\
\hline inclusão & $-0,5369$ & \multicolumn{4}{|l|}{0,2882} \\
\hline liquipublico & 0,0188 & \multicolumn{4}{|l|}{0,0003} \\
\hline liquibanco & $-0,2944$ & \multicolumn{4}{|l|}{0,0866} \\
\hline \multicolumn{3}{|c|}{ Desenvolvimento do Sistema Financeiro } & 0,1089 & 0,3880 & 0,04226 \\
\hline lrendapcpobre & 0,0342 & \multicolumn{4}{|l|}{0,0011} \\
\hline gini & $-0,4356$ & \multicolumn{4}{|l|}{0,1897} \\
\hline desemprego & $-0,1654$ & \multicolumn{4}{|l|}{0,0273} \\
\hline informal & $-0,2842$ & \multicolumn{4}{|l|}{0,0807} \\
\hline anosestudo & $-0,5419$ & \multicolumn{4}{|l|}{0,2936} \\
\hline \multicolumn{6}{|c|}{ Renda Domiciliar per capita média pobre } \\
\hline
\end{tabular}

Fonte: Elaboração própria

que ele representa a variância no conjunto relacionado à renda domiciliar per capita média do pobre atribuída à variabilidade do conjunto relativo ao desenvolvimento do sistema financeiro e que, de certa forma, a população pobre não participa, de uma maneira mais efetiva do sistema financeiro, pode-se inferir que um poder explicativo em torno de $28 \%$ pode ser considerado razoável, pois esta é uma estatística que 
denota um impacto específico e direto sobre as variáveis vinculadas à renda. Ademais, isto confirma a percepção de que a variância do composto relacionado à pobreza proveniente do conjunto relacionado ao desenvolvimento do sistema financeiro deve, realmente, ser menor, uma vez que a covariância com a renda domiciliar per capita média do pobre foi menor do que com a renda domiciliar per capita média. Como nos outros casos, a segunda dimensão canônica não demonstrou significância prática, com índice de redundância em torno de 0,04 para ambas as variáveis dependentes e explicativas.

As Tabelas 3 a 5 demonstram, para a primeira dimensão canônica, que a variável estatística independente (Desenvolvimento do Sistema Financeiro) mostrou índices de redundância bem menores, 0,1869, 0,1954 e 0,1850 quando consideradas as variáveis relacionada à taxa de pobreza, à renda domiciliar per capita média e à renda domiciliar per capita média do pobre, respectivamente. Ainda assim, como esta estatística traduz a variância na variável independente explicada pelos conjuntos de variáveis dependentes, pode-se considerar esses resultados como aceitáveis. O resultado de que as variáveis relacionadas à renda domiciliar per capita média explicam cerca de $20 \%$ da variância das variáveis relacionadas ao desenvolvimento do sistema financeiro não é um inexpressivo, como ocorre no caso da segunda dimensão canônica (índice de redundância de 0,051). Dentro dessa mesma lógica, as variâncias do desenvolvimento do sistema financeiro explicada pelas variáveis relacionadas à taxa de pobreza e pelas variáveis relativas à renda domiciliar per capita média do pobre, ainda que tenham apresentado valores menores $(0,1869$ e 0,1850) para a primeira dimensão canônica, não devem também ser negligenciadas. De tudo, é possível inferir, mesmo sob uma relação bidirecional, que a variabilidade do conjunto de variáveis correlatas ao desenvolvimento do sistema financeiro explica mais a variância do composto de variáveis relacionada à pobreza e à renda, do que o inverso.

Além disso, conforme pode ser percebido ao longo desta análise, a primeira dimensão canônica foi capaz de explicar o comportamento das correlações entre as variáveis dependentes relativas à pobreza, renda domiciliar per capita média e renda domiciliar per capita média do pobre e, as variáveis independentes referentes ao desenvolvimento do sistema financeiro.

\subsection{Importância relativa das variáveis}

Uma vez constatada a significância da relação canônica e que os valores da raiz canônica e do índice de redundância são admitidos como válidos para a primeira dimensão, é importante avaliar a importância relativa de cada variável, o que geralmente é feito por meio dos pesos canônicos (coeficientes padronizados) das cargas canônicas e das cargas canônicas cruzadas. Contudo, na análise destes 
indicadores, apenas as primeiras dimensões canônicas serão consideradas, uma vez que foram aquelas que, para quaisquer das variáveis dependentes consideradas, apresentaram correlações canônicas mais expressivas e índices de redundância bastante superiores aos das demais funções.

Os pesos canônicos traduzem a correlação parcial de uma determinada variável com sua respectiva variável canônica. Entretanto, conforme ponderam Hair et al. (1998), torna-se necessária certa dose de precaução ao interpretar a contribuição relativa de uma determinada variável por meio do seu peso canônico, dada a grande instabilidade ou variabilidade que demonstram de uma amostra para outra. Nesse sentido, dados os problemas de instabilidade apresentados pelos pesos canônicos e, seguindo uma prática frequente neste tipo de procedimento econométrico, optou-se por considerar apenas as cargas canônicas para interpretação dos resultados.

\subsubsection{Cargas canônicas}

As cargas canônicas medem a correlação linear entre as variáveis dependentes ou independentes e suas respectivas variáveis canônicas, refletindo, dessa forma, a variância que uma determinada variável compartilha com seu conjunto. Nesse sentido, quanto maior a carga canônica, maior a importância da variável para o conjunto de variáveis canônicas. Pelos resultados da Tabela 6, as variáveis mais importantes no conjunto canônico independente, ou seja, relacionado ao desenvolvimento financeiro, foram o acesso e a inclusão, para quaisquer dos conjuntos de variáveis dependentes considerados. Ainda que, conforme ponderam Lambert e Duran (1975), as cargas canônicas minimizem os problemas de multicolinearidade, por considerar cada função canônica independente e a correlação de cada variável dentro do conjunto separadamente, deve-se levar em conta que as variáveis de acesso e de inclusão, guardam certa interdependência com o tamanho, a eficiência e as preferências pela liquidez do público e dos bancos, o que pode ter concorrido para que captassem boa parte da variância compartilhada deste composto canônico.

Especificamente no caso do conjunto dependente relacionado à pobreza, as variáveis que se mostraram mais relevantes para o grupo, em termos da variância compartilhada, foram a taxa de pobreza (taxapobreza), o grau de informalidade (informal) e a média de anos de estudos (anosestudo). No grupo de variáveis relacionadas à renda domiciliar per capita média, as variáveis que mostraram maior variância compartilhada foram a renda domiciliar per capita média (rendapc) e o grau de informalidade (informal). Considerando como variável dependente o conjunto relativo à renda domiciliar per capita média do pobre, as maiores variâncias compartilhadas foram verificadas no grau de informalidade na média de anos de estudos. 
Tabela 6

Cargas canônicas para a primeira dimensão

\begin{tabular}{|c|c|c|c|}
\hline \multicolumn{2}{|c|}{ Desenvolvimento Financeiro } & \multicolumn{2}{|c|}{ Pobreza } \\
\hline Variável & Carga Canônica & Variável & Carga Canônica \\
\hline ltamanho & $-0,2618$ & taxapobreza & 0,9765 \\
\hline leficiência & 0,5182 & gini & 0,4926 \\
\hline acesso & $-0,8699$ & informal & 0,9176 \\
\hline inclusão & $-0,5869$ & desemprego & 0,0037 \\
\hline liquipublico & 0,1340 & anosestudo & $-0,8445$ \\
\hline liquibanco & 0,1649 & taxarendapc & $-0,0739$ \\
\hline \multicolumn{2}{|c|}{ Desenvolvimento Financeiro } & \multicolumn{2}{|c|}{ Renda Domiciliar per capita média } \\
\hline ltamanho & 0,4131 & lrendapc & 0,9953 \\
\hline leficiência & $-0,4630$ & gini & $-0,3887$ \\
\hline acesso & 0,8768 & informal & $-0,9152$ \\
\hline inclusão & 0,7055 & desemprego & 0,0216 \\
\hline liquipublico & $-0,2097$ & anosestudo & 0,8375 \\
\hline liquibanco & $-0,2100$ & & \\
\hline \multicolumn{2}{|c|}{ Desenvolvimento Financeiro } & \multicolumn{2}{|c|}{ Renda Domiciliar per capita média do pobre } \\
\hline ltamanho & 0,2800 & lrendapcpobre & 0,5728 \\
\hline leficiência & $-0,5439$ & gini & $-0,4488$ \\
\hline acesso & 0,7821 & informal & $-0,9346$ \\
\hline inclusão & 0,7044 & desemprego & 0,0871 \\
\hline liquipublico & $-0,1734$ & anosestudo & 0,9279 \\
\hline liquibanco & $-0,0803$ & & \\
\hline
\end{tabular}

Assim, na primeira dimensão, para quaisquer das variáveis dependentes e explicativas, as estimativas obtidas para as cargas canônicas mostraram-se compatíveis com aquelas obtidas para os pesos canônicos, denotando uma coerência dos resultados, quer seja no sentido de traduzir a correlação parcial de cada variável com sua respectiva variável canônica, bem como de refletir a variância que a variável compartilha com seu respectivo conjunto. Em parte, isso pode ser atribuído às similaridades existentes nos conjuntos de variáveis independentes, já que os indicadores que afetam a taxa de pobreza, a renda domiciliar per capita média e a renda domiciliar per capita média dos pobres são, basicamente, os mesmos. Não obstante, isto reflete a importância conferida a algumas variáveis, tais como o grau de informalidade e a média de anos de estudos, além da taxa de pobreza e da renda domiciliar per capita, como determinantes para explicação da variância da renda e da pobreza no Brasil no período em consideração.

Isto confirma tanto a perspectiva teórica quanto a constatação empírica de diversos estudos ${ }^{10}$, vale dizer, os trabalhadores do setor informal têm rendimentos

(10) Como, por exemplo, Cardoso Jr. (1999). 
inferiores aos assalariados e integram a parcela da população com níveis de renda mais baixos, afetando, especialmente, a renda per capita média e a taxa de pobreza. Não menos importante, pelo seu reconhecido papel na determinação do nível de renda da população, a variável média de anos de estudos da população de 25 anos e mais, destacou-se também como determinante na variância compartilhada dos compostos canônicos relacionados à taxa de pobreza e renda domiciliar per capita da população pobre, já que, comprovadamente, níveis de escolaridade mais elevados, em geral, estão relacionados a rendimentos médios maiores e, portanto, a taxas de pobreza menores.

Por outro lado, os resultados obtidos para a taxa de desemprego podem, a princípio, parecerem fora de contexto, pela baixa variância compartilhada com seus respectivos compostos canônicos. Nenhum dos conjuntos dependentes apresentou valores expressivos de variância compartilhada para essa variável. Contudo, uma avaliação do comportamento da taxa de desemprego no período sob consideração mostra a forte instabilidade que caracteriza esta variável, dada a sua suscetibilidade ao desempenho macroeconômico, especialmente para uma base de dados no formato aqui considerado, fundamentada nas unidades da federação brasileira. Este parece o motivo mais plausível para o resultado obtido para a taxa de desemprego.

Contudo, ainda que as cargas canônicas sejam consideradas mais estáveis cabe, também, analisar as cargas canônicas cruzadas, como último exercício para avaliar a natureza das correlações canônicas, no sentido da determinação da importância relativa de cada variável.

\subsubsection{Cargas canônicas cruzadas}

As cargas canônicas cruzadas possibilitam uma medida mais direta das relações entre as variáveis, uma vez que correlaciona, diretamente, cada variável observada, dentre as dependentes e independentes, com a variável canônica oposta. Pela Tabela 7 é possível inferir, a partir dos resultados obtidos para a dimensão 1, que para a variável dependente relacionada à pobreza, as variáveis taxa de pobreza, grau de informalidade, média de anos de estudos e índice de Gini apresentam considerável correlação ${ }^{11}$ com a variável canônica relativa ao sistema financeiro de, respectivamente, $0,8491,0,7979,0,7343$ e 0,4283 . Isso denota que $72 \%$ da variância na taxa de pobreza, $63,7 \%$ da variância no grau de informalidade, $53,9 \%$ e da variância na media de anos de estudos e $18,3 \%$ do grau de desigualdade são explicados pelo desenvolvimento do sistema financeiro ${ }^{12}$.

(11) De acordo com Lambert e Duran (1975, p. 472), os valores considerados válidos para as cargas canônicas são arbitrários. Contudo, valores no intervalo entre 0,28 e 0,45 são os mais aceitos em diversos estudos, com uma maior prevalência de 0,30 .

(12) Esse percentual foi obtido elevando as cargas canônicas cruzadas ao quadrado para cada uma das variáveis mencionadas. 
Tabela 7

Cargas canônicas cruzadas para a primeira dimensão

\begin{tabular}{|c|c|c|c|}
\hline \multicolumn{2}{|c|}{$\begin{array}{c}\text { Correlação entre as variáveis } \\
\text { independentes e a variável canônica } \\
\text { dependente }\end{array}$} & \multicolumn{2}{|c|}{$\begin{array}{c}\text { Correlação entre as variáveis dependentes e a } \\
\text { variável canônica independente }\end{array}$} \\
\hline \multicolumn{2}{|c|}{ Desenvolvimento Financeiro } & \multicolumn{2}{|c|}{ Pobreza } \\
\hline Variável & Carga Canônica & Variável & Carga Canônica \\
\hline ltamanho & $-0,2227$ & taxapobreza & 0,8491 \\
\hline leficiência & 0,4506 & gini & 0,4283 \\
\hline acesso & $-0,7564$ & informal & 0,7979 \\
\hline inclusão & $-0,5103$ & desemprego & 0,0032 \\
\hline liquipublico & 0,1165 & anosestudo & $-0,7343$ \\
\hline liquibanco & 0,1434 & taxarendapc & $-0,0643$ \\
\hline \multicolumn{2}{|c|}{ Desenvolvimento Financeiro } & \multicolumn{2}{|c|}{ Renda Domiciliar per capta média } \\
\hline ltamanho & 0,3622 & lrendapc & 0,8728 \\
\hline leficiência & $-0,4060$ & gini & $-0,3409$ \\
\hline acesso & 0,7689 & informal & $-0,8025$ \\
\hline Inclusão & 0,6187 & desemprego & 0,0189 \\
\hline liquipublico & $-0,1839$ & anosestudo & 0,7344 \\
\hline liquibanco & $-0,1842$ & & \\
\hline \multicolumn{2}{|c|}{ Desenvolvimento Financeiro } & \multicolumn{2}{|c|}{ Renda Domiciliar per capta média do pobre } \\
\hline ltamanho & 0,2394 & lrendapcpobre & 0,4898 \\
\hline leficiência & $-0,4651$ & gini & $-0,3837$ \\
\hline acesso & 0,6687 & informal & $-0,7992$ \\
\hline inclusão & 0,6023 & desemprego & 0,0745 \\
\hline liquipublico & $-0,1483$ & anosestudo & 0,7935 \\
\hline liquibanco & $-0,0687$ & & \\
\hline
\end{tabular}

Fonte: Elaboração própria.

Tendo em vista as variáveis concernentes à renda domiciliar per capita média, as maiores cargas canônicas cruzadas foram apresentadas pela renda domiciliar per capita $(0,8728)$, pelo grau de informalidade $(-0,8025)$, pela média de anos de estudos $(0,7344)$ e pelo índice de Gini $(-0,3409)$, o que indica que o conjunto do desenvolvimento do sistema financeiro explica, respectivamente, 76\%, 64\%, 54\% e $11 \%$ da variância nestas variáveis. O relativamente baixo poder preditivo da taxa de desemprego pode ser atribuído aos motivos já comentados anteriormente. No caso do composto relacionado à renda domiciliar per capita média do pobre, sobressaíram as cargas canônicas cruzadas das variáveis de grau de informalidade $(-0,7992)$, média de anos de estudos $(0,7935)$, renda domiciliar per capita média do pobre $(0,4898)$ e índice de Gini $(-0,3837)$. Isto exprime a importância do desenvolvimento do sistema financeiro para o composto relacionado à renda do pobre, pela capacidade de explicar $63,8 \%$ da variância da informalidade, $62,9 \%$ da variância da média de anos de estudos da população de 25 anos e mais, $24,9 \%$ da renda domiciliar per capita média do pobre e $14,7 \%$ do índice de desigualdade. 
Para as variáveis independentes, o acesso e a inclusão também mostraram uma boa correlação de, respectivamente, $-0,7564$ e $-0,5103$, com a variável canônica dependente relacionada à taxa de pobreza. Por sua vez, o tamanho do sistema financeiro e as preferências pela liquidez do público e dos bancos apresentaram baixas correlações com a variável canônica dependente (-0.2277, 0.1165 e 01434, respectivamente), enquanto a eficiência do sistema financeiro $(0,4506)$ apresentou uma sinalização oposta à previsão teórica. É possível, portanto, inferir que a variável canônica dependente, isto é, a pobreza, explica $57,2 \%$ da variância no acesso e 26,4\% da variância na inclusão.

Levando-se em consideração a renda domiciliar per capita média sobressaem, também, as cargas canônicas cruzadas das variáveis de acesso $(0,7689)$, inclusão $(0,6187)$, acrescida do tamanho $(0,3622)$, no conjunto relacionado ao desenvolvimento do sistema financeiro. Tais resultados são indicativos de que a variância nestas variáveis explicadas pela renda domiciliar per capita média é de, respectivamente, $59 \%, 38,2 \%$ e $13 \%$. No caso da renda domiciliar per capita média do pobre, os resultados foram similares, com as variáveis canônicas cruzadas acesso $(0,6687)$ e inclusão $(0,6023)$ apresentando as maiores cargas canônicas denotando, portanto, variâncias explicadas pela renda domiciliar per capita média do pobre de, respectivamente $44,7 \%$ e $36,2 \%$.

As preferências pela liquidez do público e dos bancos, assim como o tamanho, apresentaram baixas cargas canônicas em quase todas as situações ${ }^{13}$, o que indica que tanto o composto relacionado à taxa de pobreza, quanto os compostos relativos à renda domiciliar per capita média e renda domiciliar per capita média do pobre têm baixa capacidade de explicar a variância nestas variáveis. A variável eficiência, ainda que tenha apresentado uma correlação canônica cruzada não desprezível (acima de 0,40), para quaisquer das variáveis dependentes consideradas, não demonstrou, contudo, sinalização em conformidade com a previsão da teoria.

Deve-se destacar ainda que, para a maioria das variáveis, a sinalização é coerente com o previsto pela teoria, ou seja, as variáveis que compõem o desenvolvimento do sistema financeiro relacionadas ao acesso, à inclusão e ao tamanho do setor apresentaram uma relação inversa com as variáveis correlatas à taxa de pobreza, enquanto as preferências pela liquidez denotaram uma relação direta. Isso sinaliza que o aumento do acesso, da inclusão e do tamanho do setor financeiro, bem como a redução das preferências pela liquidez, implicam em taxa de pobreza, índice de gini, grau de informalidade e taxa de desemprego menores, assim como em média de anos de estudos e taxa de crescimento da renda domiciliar per capita maiores. Similarmente, a sinalização no sentido inverso também pode ser

(13) Exceção para a variável tamanho que apresentou carga canônica superior a 0,30, quando considerada a variável dependente renda domiciliar per capita média. 
observada quando considerados os conjuntos relacionados à renda domiciliar per capita média e renda domiciliar per capita média dos pobres. As variáveis financeiras de tamanho, acesso e eficiência apresentaram sinalização positiva indicando, portanto, uma correlação direta com os conjuntos da renda, enquanto as preferências pela liquidez do público e dos bancos apresentaram sinalização negativa, denotando uma relação no sentido inverso.

Estes resultados são, portanto, sugestivos de que o efeito da pobreza e da renda sobre o desenvolvimento do sistema financeiro está mais diretamente relacionado ao acesso e à inclusão que, de certa forma, dependem do tamanho do setor e das preferências pela liquidez do público e dos bancos. No conjunto da análise, a ideia geral é a de que o desenvolvimento do sistema financeiro demonstra ter um poder de predição da variância da pobreza e da renda maior do que o poder explicativo da variância do sistema financeiro pela pobreza e renda. Não obstante, não há como desconsiderar que a análise da correlação canônica mostrou um sentido de variância bidirecional entre os compostos relacionados ao desenvolvimento do sistema financeiro e aqueles correlatos à pobreza, renda domiciliar per capita média e renda domiciliar per capita média do pobre, ainda que o primeiro tenha apresentado mais poder preditivo que o segundo ${ }^{14}$.

\section{Conclusão}

Este trabalho analisou o impacto do desenvolvimento do sistema financeiro sobre a pobreza e a renda domiciliar per capita no Brasil entre 1995-2008. Foi possível inferir que: i) a maioria das dimensões canônicas demonstrou significância estatística, quer seja para as variáveis relacionadas à pobreza, à renda domiciliar per capita média ou à renda domiciliar per capita média do pobre, o que confirma a hipótese de correlação com o conjunto de variáveis do desenvolvimento do sistema financeiro; ii) aproximadamente $35 \%$ da variância nas variáveis dependentes, referentes à pobreza, pode ser atribuída à variabilidade do conjunto relativo ao desenvolvimento do sistema financeiro; iii) a maior variância (de 41,2\%) verificada no conjunto relacionado à renda domiciliar per capita média, devido à variabilidade no composto de variáveis representativas do sistema financeiro denota, em certo sentido, seu impacto positivo sobre o crescimento econômico, já demonstrado por

(14) A validação dos resultados da análise da correlação canônica pode ser realizada por meio da partição da amostra e/ou da análise de sensibilidade, com base na exclusão de variáveis independentes visando verificar a estabilidade da correlação explicada pelo modelo. A análise da sensibilidade foi conduzida excluindo as variáveis eficiência, inclusão e tamanho, para todas as variáveis canônicas dependentes. De uma forma geral, as cargas canônicas demonstraram boa estabilidade em todas as situações em que foram excluídas uma das variáveis independentes. Tanto a variável canônica representativa dos indicadores de pobreza e das rendas, quanto do desenvolvimento do sistema financeiro não apresentaram variações significativas na raiz canônica e no índice de redundância, ou na medida prática da relação com os indicadores da variável canônica oposta, o que valida os resultados obtidos. 
diversos estudos, e suas repercussões favoráveis sobre a renda; iv) cerca de $28 \%$ da variância na renda domiciliar per capita média do pobre é atribuída à variabilidade do conjunto relacionado ao sistema financeiro, o que pode ser considerado um indicador razoável, na medida em que, em geral, esta parcela da população não participa, ainda, de forma efetiva dos benefícios que podem ser gerados pelo uso dos serviços financeiros.

Os resultados da análise da correlação canônica possibilitaram, ainda, inferir que, embora baixas, as variâncias do conjunto de variáveis do desenvolvimento do sistema financeiro proveniente da variabilidade dos compostos relativos à pobreza, à renda domiciliar per capita média e à renda domiciliar per capita média do pobre, não são inexpressivas, o que sugere um sentido de causalidade bidirecional. Todavia, deve-se sublinhar que o desenvolvimento do sistema financeiro apresentou um poder de predição da variância da pobreza e da renda maior do que o poder explicativo da variância do sistema financeiro pela pobreza e renda.

No conjunto geral, foi possível perceber que os resultados reportados pela análise da correlação canônica evidenciaram que os compostos de variáveis relacionados à pobreza e à renda guardam considerável correlação com a variável canônica relativa ao desenvolvimento do sistema financeiro. Desta forma, o desenvolvimento do sistema financeiro demonstrou ter um bom poder preditivo da variância do conjunto de variáveis relacionadas à pobreza e renda.

O papel crucial que o desenvolvimento do setor financeiro desempenha na redução da pobreza, quer seja de forma direta, por meio da ampliação do acesso e da inclusão financeira da parcela da população de menores níveis de renda, ou, indiretamente, via promoção do crescimento econômico, constitui-se em forte apelo à consecução e implementação de políticas capazes de garantir a efetiva inserção do pobre no sistema financeiro nacional. Para tanto, torna-se essencial o desenvolvimento de estudos futuros que elucidem, dentre outros aspectos, as ações e programas que devem ser adotados pelo sistema financeiro como mecanismos efetivos e eficazes de redução da pobreza, assim como a correlação entre políticas específicas do setor financeiro, a ampliação da renda e redução da pobreza.

\section{Referências bibliográficas}

AGHION, P.; BOLTON, P. A theory of trickle-down growth and development. Review of Economic Studies, v. 64, n. 2, p. 151-172, 1997.

AKHTER, S.; DALY, J. J. Finance and poverty: evidence from fixed effect vector decomposition. Emerging Market Review, v. 10, n. 3, p. 191-203, 2009.

ALMEIDA, D. B. C; JAYME JR. F. G. Bank consolidation and credit in Brazil (1995-2004). Cepal Review, n. 95, p. 155-171, 2008. 
AMADO, A. M. A questão regional e o sistema financeiro no Brasil. Estudos Econômicos, v. 27, n. 3, p.417-440, 1997.

. Impactos regionais do processo de reestruturação bancária do início dos anos 1990. In: CROCCO, M.; JAYME JR., F. G. Moeda e território: uma interpretação da dinâmica regional brasileira. 1. ed. Belo Horizonte: Autêntica, 2006, Parte III: Estudos de caso sobre o Brasil, p.147-169.

BANERJEE, A. V.; NEWMAN, A. F. Occupational choice and the process of development. Journal of Political Economy, v. 101, n. 2, p. 274-298, 1993.

BARRA, C.; CROCCO, M. Moeda e espaço no Brasil: uma análise pós-keynesiana. Belo Horizonte: UFMG/Cedeplar, 2002. 50p. (Texto para Discussão, 181).

BECK, T.; DEMIRGÜÇ-KUNT, A.; LEVINE, R. Finance, inequality and the poor. Journal of Economic Growth, v. 12, n. 1, p. 27-49, 2007.

BEMERGUY, C. B.; LUPORINI, V. Desenvolvimento financeiro e desigualdade de renda: evidência para o caso brasileiro. Rio de Janeiro: UFF/Economia, 2006, 22p. (Texto para Discussão, 207).

BERTHELEMY, J. C.; VAROUDAKIS, A. Economic growth, convergence clubs, and the role of financial development. Oxford Economic Papers, n. 48, p. 300-328, 1996.

BITTENCOURT, M. F. M. Financial development and inequality: Brazil 1985-99. England: Univerty of Bristol/Department of Economics, 2006. 24p.

BRASIL. Banco Central do Brasil. Relatório de Inclusão Financeira. Brasília, 2010. n.1, p.1-125.

BURGESS, R; PANDE, R. Do rural banks matter? evidence from the Indian social banking experiment. American Economic Review, v. 95, n. 3, p. 780-795, 2005.

CARDOSO JR., J. C. Estrutura setorial-ocupacional do emprego no Brasil e evolução do perfil distributivo nos anos 90. Rio de Janeiro: Ipea, 1999. 34p. (Texto para Discussão, 655).

CAVALCANTE, A.; CROCCO, M.; BRITO, M. A. de. Impactos macroeconômicos na variação regional da oferta de crédito. In: ENCONTRO NACIONAL DE ECONOMIA, 33, 2005, Natal. Anais eletrônicos... Natal: Anpec, 2005. Disponível em: http://www.anpec.org.br/encontro 2005.htm. Acesso em: 13 set. 2010.

; CROCCO, M.; JAYME JR., F. G. Preferência pela liquidez, sistema bancário e disponibilidade de crédito regional. Belo Horizonte: UFMG/Cedeplar, 2004. 22p. (Texto para Discussão, 237).

CLAESSENS, S.; FEIJEN, E. Finance and hunger: empirical evidence of the agricultural productivity channel. World Bank Policy Research, 2006. (Working 
Paper, 4080). Disponível em: http://ssrn.com/abstract=950135. Acesso em: 16 abr. 2010.

CLARKE, G.; XU, L. C. X.; ZOU, HENG-FU, Z. Finance and income inequality: test of alternative theories. 2003. p. 1-26. (Policy Research Working Paper, n. 2984).

CROCCO, M. et al. Polarização regional e sistema financeiro. In: CROCCO, M. JAIME JR., F. G. Moeda e território: uma interpretação da dinâmica regional brasileira. 1. ed. Belo Horizonte: Autêntica, 2006. p. 231-269.

; CAVALCANTE, A.; BARRA, C. Money and space: the behavior of liquidity preference of banks and public in a peripheral country. Belo Horizonte: UFMG/Cedeplar, maio 2003. 30p. (Texto para discussão, 196).

DOLLAR, D.; KRAAY, A. Growth is good for the poor. Journal of Economic Growth, v. 7, p. 195-225, 2002.

DOW, S. C. The regional composition of the money multiplier process. Scottish Journal of Political Economy, v. 29, n. 1, p. 22-44, Feb. 1982.

FIELDS, G. S. Distribution and development: a new look at the developing world. 1. ed. Cambridge, MA: MIT Press and the Russell Sage Foundation, 2001.

GALOR, O.; ZEIRA, J. Income distribution and macroeconomics. The Review of Economic Studies, v. 60, n. 1, p. 35-52, Jan. 1993.

GREENWOOD, J. JOVANOVIC, B. Financial development, growth, and the distribution of income. The Journal of Political Economy, v. 98, n. 5, p. 1076-1107, Oct. 1990.

GUILLAUMONT, J.; KPODAR, K. Financial development, financial instability and poverty. France: Université d'Auvergne/CERDI-CNRS, Oct. 2005. 35p. (CSAE WPS/2005-09).

HAIR, J. F. et al. Canonical correlation analysis: a supplement to multivariate data analysis. Disponível em: www.mvstats.com/Downloads/Supplements/Canonical Correlation 7e.pdf. Acesso em: 22 mar. 2010.

JALILIAN, H.; KIRKPATRICK, C. Financial development and poverty reduction in developing countries. International Journal of Finance and Economics, v. 7, n. 2, p. 97-108, Apr. 2002.

KUMAR, A. Access to financial services in Brazil. Washington, D.C: The World Bank, 2004. 619p.

KUZNETS, S. Economic growth and income inequality. American Economic Review, v. 45, n. 1, p. 1-28, Mar. 1955. 
LAMBERT, Z. V.; DURAND, R. M. Some precautions in using canonical analysis. Journal of Marketing Research, v. 12, p. 468-475, Nov. 1975.

McKINNON, R. I. Money and capital in economic development. Washington, D.C.: Brookings Institution, 1973. 184p.

MYRDAL, G. Economic theory and underdeveloped regions. London: Gerald Duckworth \& CO, 1957. 167p.

PIKETTY, T. The dynamics of the wealth distribution and the interest rate with credit rationing. The Review of Economic Studies, v. 64, n. 2, p. 172-189, 1997.

RODRIGUEZ FUENTES, C. J. Credit availability and regional development. Papers in Regional Science. v. 77, n. 1, p. 63-75, Jan. 1998.

ROMERO, J. P.; JAYME JR., F. G. Crédito, preferência pela liquidez e desenvolvimento regional: o papel dos bancos públicos e privados no sistema financeiro brasileiro (2001-2006). In: ENCONTRO NACIONAL DE ECONOMIA POLÍTICA, 14, 2009, São Paulo. Anais... São Paulo, set. 2009.

SHAW, E. S. Financial deepening in economic development. New York: Oxford University Press, 1973. 260p.

THOMPSON, B. Canonical correlation analysis. In: GRIMM, L. G.; YARNOLD, P. R. Reading and understanding more multivariate statistics. Washington, DC: American Psychological Association, 1991.

ZHUANG, J. et al. Financial sector development, economic growth, and poverty reduction: a literature review. Philippines: Asian Development Bank, Oct. 2009. 39p. (ADB Economics Working Paper Series, n. 173). 